\title{
Intersex and gender controversies
}

\author{
Satyajit Patra* and Araromi Adewale Andrew \\ American International Medical University, Bosejour Road, Gros Islet, Saint Lucia, WI, USA
}

There are few easy answers when it comes to gender and gender identity. However, to some group of people, the answer may seem much more complicated. This is because some people are found to be intermediate between the two genders. Such people are referred to as "intersex" which can be perceived as sex developmental defect. This article gives a review of the real meaning of intersex as well as social and psychological issues associated with it. Several factors have been identified by scientists in classifying human gender. Biological sex may be ascertained based on certain characteristics which include external genitalia, internal reproductive anatomy, sex chromosomes as well as the type of gonads present (testis or ovaries) [1].

As University of Oregon professor and intersex expert Elizabeth Reis writes in her book Bodies in Doubt, "In the United States and most other places, humans are men or they are women; they may not be neither or both. Yet not all bodies are clearly male or female." That may suggest that a child has typical female chromosomes and ovaries but external bodies parts of a male [2]. The Council of Europe, in an explanatory memorandum to resolution (1952) on children's right to physical integrity explains intersex as atypical and or external anatomical characteristics where features usually regarded as male or female may be mixed to some degree. This was however stated as a naturally occurring variation in human and not necessarily a medical condition. It is worthy of note that such variation may cause ambiguity of genitalia, and combinations of phenotype and genotype other than XY male and XX female. However, in 2003, the Heinrich Bill Foundation published an analysis of the human rights of intersex people written by Dr. Dan Christian Ghattas. He holds that intersex individuals are considered individuals with a "disorder," in all areas in which Western medicine prevails. They are more or less treated as sick or abnormal depending on the society concerned. Intersex tends to get far less attention as opposed to transgender, gay and lesbianism and yet it is a condition that has great social and psychological effects on their victims.

Most individuals affected tend to conceal it from others. 'The truth is I have been living with secrets my whole life, 'I was born intersex and named David Roy Fitch at birth.' Taylor Lianne Chandler wrote on her facebook page. It is not uncommon to see some intersex individuals who were raised as either male or female get to identify with another gender later in life. There are varieties of conditions that have been associated with intersex of which Congenital Adrenal Hyperplasia(CAH) and Androgen Insensitivity Syndrome(AIS) have been greatly implicated.

Congenital Adrenal Hyperplasia is the most common cause of female pseudointersexuality. Although, it can as well affect males. In this condition, there is excessive virilization which results to a condition known as vaginal agenesis, and a penis which is active, making penetrating intercourse possible. However, affected females are capable of getting pregnant and giving birth and not get pregnant and give birth.. In mild cases, the condition results into clitoris which is slightly larger, while in more complicated cases, it could result into ambiguous genitalia as a result of 21-hydroxylase deficiency. Most children affected, often think of themselves as females when they are old enough to have knowledge of the difference. Individuals with XX chromosomes which are influenced by 17alpha-hydroxylase deficiency are born with female internal and external anatomy, but at puberty, no sex hormone is being produced by the ovaries and the adrenal gland thereby inhibiting breast development and the growth of pubic hair [3].

Androgen Insensitivity Syndrome often called testicular feminization is another condition being implicated in intersex individuals which results in total or partial incapability of cells to respond to androgens. The inability of the cells to respond to the presence of androgenic hormones can weaken the masculinization of male genitalia, in the developing embryo as well as the development of secondary features at puberty, but does not significantly affect secondary sexual development in female and genitalia. This condition may however be grouped into three forms based on the degree of genital masculinization and or phenotype [4].

Complete AIS is the most severe form and it totally affects the ability of a genetic male to recognize androgens. Individuals with this condition grow up as females and may not know their geneticstatus until they reach puberty, where they experience herniation as a result of their undescended testis combined with amenorrhea in their late teens. This condition makes such male individual to have female phenotype with normal external secondary characteristics. The insufficiently developed testicles and lack of ovaries and uterus results into infertility in such individual. However, the lower part of vaginal will be observed based on its different embryological development.

Mild forms of this condition usually pose no developmental issues and such individuals are raised as males. The degree of impairment is not sufficient to impair spermatogenesis or secondary sexual features development at puberty. Female genital and sexual development is not significantly affected by the insensitivity to androgens, though mild spermatogenic defect and or reduced terminal hair may be observed. Partial androgen insensitivity on the other hand may be observed in individuals whose body is partially receptive to androgens, which results into varying degree of virilization. This form can result in genital ambiguity, due to limited metabolism of the androgens produced by the testes. Clitoromegaly; or a micropenis, may result in ambiguous genitalia, also, hypospadias and cryptorchidism may be present.

Other causes may include true gonadal intersex where both testes

Correspondence to: Satyajit Patra, American International Medical University, Bosejour Road, Gros Islet, Saint Lucia, WI, USA, E-mail: dr.patra@aimu-edu.us

Received: August 10, 2015; Accepted: September 11, 2015; Published: September 14, 2015 
and ovaries may be in the same gonad(ovotestis) or an ovary and a testis may be observed. The individual may have XX, XY chromosome or both. The external genitalia may be male, female or ambiguous. This condition may also be referred to as true hermaphroditism. Complex or underdetermined intersex disorder of sex development may also occur as a result of chromosomal aberration. Such anomalies include 45XO, 47XXY, 47XXX with a loss and extra gain of chromosome respectively. These disorders do not cause discrepancy between external and internal genitalia. However, there may be problems with sex hormone levels, overall sexual development, and altered number of sex chromosomes.

There are many challenges as well as gender controversies being faced by people with intersex conditions and their families. Intersex conditions found out later in life usually manifest in early adolescence. Delayed or absent signs of puberty may be the first indication that an intersex condition exists. For example, complete androgen insensitivity may first become apparent when Intersex conditions, whether discovered at birth or later in life, can be very challenging for affected persons and their families. Medical information about intersex conditions and their implications are not often understood easily. Persons with intersex conditions and their families may also experience feelings of shame, isolation or depression [5].

Parents of children with intersex conditions sometimes wonder if they should tell their children about their condition and at what age. Intersex experts often suggests that parents and care providers tell children with intersex conditions about their condition throughout their lives as soon as they are old enough to know.

Multiple intersex athletes have been humiliated, and withdrawn from competitions after the discovery of their intersex status. Such athletes include Foekje Dillema, Erik Schineggger and Pinki Pramanik. Santhai Soundarajan, an Indian runner was stripped of her medal at the 2006 Asian games in a gender controversy. In September 2007, she was reported to have attempted suicide. It was reported that she later established her own academy and also took up coaching with the regional government [6].

Caster Semenya is another icon to be reckoned with in the world of Athletics. She is a South African middle-distance runner and world champion. She won gold in the women's 800 metres at the 2009 World Championships in the final. Semenya also won silver medals at the 2011 World Championships and the 2012 Summer Olympics, both in the 800 metres. Following her victory at the 2009 World Championships, it was declared that she had been subjected to gender testing due to her deep voice and muscle build. She was withdrawn from international competition until July 2010 when The International Association of Athletics Federation (IAAF) cleared her to return to the competition and continue competing as a woman. Although the results of the gender testing was not made known to the public for private reasons [7].

Options to manage intersex traits include surgery, hormone treatment, and psychosocial support. A team of health care professionals with expertise in intersex preferably should work in unison to understand and treat children with intersex and to understand, counsel, and support the entire family. Parents should understand controversies and changes in treating intersex in recent years. In the past, the prevailing opinion was that it was generally best to assign a gender as soon as possible, usually based on the observed external genitalia rather than the chromosomal gender, and to instruct the parents to have no ambiguity in their minds as to the gender of the child. Prompt surgery was often recommended. Ovarian or testicular tissue from the other gender would be removed. It was considered easier to reconstruct female genitalia than functioning male genitalia, so if the "correct" choice was not free from ambiguity, the child was often assigned to be a girl.

In recent times, the opinion of many experts has changed. Greater respect for the complexities of female sexual functioning had led them to resolve that suboptimal female genitalia may not be inherently better than suboptimal male genitalia, even if the reconstruction is easier. Other factors may be more important in gender satisfaction than functioning external genitals. Chromosomal, hormonal, psychological, neural and behavioral factors can all influence gender identity. This had made many experts to now delay definitive surgery for as long as healthy, and ideally involving the child in the gender decision [8].

Without any iota of doubt, intersex will remain a complex issue, and its treatment has short and long term consequences. The best answer will depend on many factors, including the main cause of the condition. It is best to take time to comprehend the issues before rushing into a decision. An intersex support group may be helpful in acquainting such families with the latest research, and also a community of other families, or individuals who have experienced similar issues.

\section{References}

1. Achermann JC, Domenice S, Bachega TA, Nishi MY, Mendonca BB (2015) Disorders of sex development: effect of molecular diagnostics. Nat Rev Endocrinol 11: 478-488. [Crossref]

2. Reis E (2012) Bodies in Doubt: An American History of Intersex, Maryland Johns Hopkins University Press.

3. Hayase M, Kojima Y, Hayashi Y, Maruyama T, Sasaki S, et al. (2006) Pseudoclitoromegaly associated with congenital prepubic sinus. Int J Urol 13: 1031-1032. [Crossref]

4. Hiort O (2013) Clinical and molecular aspects of androgen insensitivity. Endocr Dev 24: 33-40. [Crossref]

5. Diamond M, Beh HG (2008) Changes in the management of children with intersex conditions. Nat Clin Pract Endocrinol Metab 4: 4-5. [Crossref]

6. Jordan-Young RM, Sönksen PH, Karkazis K (2014) Sex, health, and athletes. BMJ 348: g2926. [Crossref]

7. Cooky C, Dworkin SL (2013) Policing the boundaries of sex: a critical examination of gender verification and the Caster Semenya controversy. J Sex Res 50: 103-111. [Crossref]

8. Lee PA, Houk CP, Ahmed SF, Hughes IA; International Consensus Conference on Intersex organized by the Lawson Wilkins Pediatric Endocrine Society and the European Society for Paediatric Endocrinology (2006) Consensus statement on management of intersex disorders. International Consensus Conference on Intersex. Pediatrics118: e488-500. [Crossref]

Copyright: (C2015 Patra S. This is an open-access article distributed under the terms of the Creative Commons Attribution License, which permits unrestricted use, distribution, and reproduction in any medium, provided the original author and source are credited. 